\title{
Effects of Integrated Physical Exercises and Gestures on Preschool Children's Foreign Language Vocabulary Learning
}

\author{
Myrto-Foteini Mavilidi ${ }^{1,2} \cdot$ Anthony D. Okely ${ }^{1}$. \\ Paul Chandler ${ }^{1} \cdot$ Dylan P. Cliff ${ }^{1} \cdot$ Fred Paas $^{1,2}$
}

Published online: 5 August 2015

(C) Springer Science+Business Media New York 2015

\begin{abstract}
Research suggests that integrating human movement into a cognitive learning task can be effective for learning due to its cognitive and physiological effects. In this study, the learning effects of enacting words through whole-body movements (i.e., physical exercise) and part-body movements (i.e., gestures) were investigated in a foreign language vocabulary task. Participants were 111 preschool children of 15 childcare centers, who were randomly assigned to one of four conditions. Participants had to learn 14 Italian words in a 4-week teaching program. They were tested on their memory for the words during, directly after, and 6 weeks after the program. In the integrated physical exercise condition, children enacted the actions indicated by the words to be learned in physical exercises. In the non-integrated physical exercise condition children performed physical exercises at the same intensity, but unrelated to the learning task. In the gesturing condition, children enacted the actions indicated by the words to be learned by gesturing while remaining seated. In the conventional condition, children verbally repeated the words while remaining seated. Results confirmed the main hypothesis, indicating that children in the integrated physical exercise condition achieved the highest learning outcomes. Implications of integrated physical exercise programs for preschool children's cognition and health are discussed.
\end{abstract}

Keywords Learning $\cdot$ Preschool children $\cdot$ Physical exercise $\cdot$ Gesturing

There is no doubt that movement is essential for human life. Research has shown substantial health, cognitive and academic benefits as a result of regular school-based physical activities

Myrto-Foteini Mavilidi

mfm351@uowmail.edu.au

1 Early Start Research Institute, University of Wollongong, NSW 2522 Wollongong, Australia

2 Institute of Psychology, Erasmus University Rotterdam, P.O. Box 1738, 3000 DR Rotterdam, The Netherlands 
(e.g., Tomporowski et al. 2008). Although these benefits have been found even when time for physical activities replaced part of the academic time (e.g., Sallis et al. 1997), the concern that time for physical activities is associated with a loss of academic time is considered a major obstacle to realizing greater involvement in school-based physical activities, and the time spent on physical education in schools is actually declining (United Nations Educational, Scientific and Cultural Organization 2015). One promising approach to relieve this concern is to investigate ways to infuse physical activity within the classroom and find ways to integrate physical activity into learning tasks without compromising learning performance or even improve it. In this study, we investigated whether such integrated physical exercises would result in better learning than non-integrated physical exercises. In addition, it was investigated whether the integrated physical exercises would lead to better learning than the same integrated activities without physical exercise. The latter type of activities refers to expressing information in gesture, which has been found effective for learning in children and young adults (e.g., Cook et al. 2008; Goldin-Meadow et al. 2001, 2009). Whereas the effects of gross motor or whole-body movements in the form of physical exercise on cognition and learning have mainly been explained by physiological mechanisms, the effects of more subtle or part-body movements, such as gestures, have mainly been explained by cognitive mechanisms.

\section{Effects of Whole-Body Movements}

An important outcome arising from the effects of physical exercise, which can be defined as "planned, structured, and repetitive bodily movement done to improve or maintain one or more components of physical fitness" (US Department of Health and Human Services 1996), is that it elicits brain changes that facilitate learning and memory (Hillman et al. 2008; LiuAmbrose et al. 2012). In an effort to uncover the underlying mechanisms of physical activity, Erickson et al. (2015) reviewed studies of physical activity on brain structure, brain function, and academic achievement. They concluded that fitter and more active children showed a range of physiological benefits (e.g., greater gray matter volume in the hippocampus, more effective brain activity patterns), performed better on tasks that require executive control and associative memory, and showed higher academic achievement. There is extensive research supporting the finding that physical activity positively correlates to cognitive performance (for reviews, see Barenberg et al. 2011; Erickson et al. 2015; Fedewa and Ahn 2011; Sibley and Etnier 2003; Tomporowski et al. 2008). It has become clear from those studies that the type of activity, level of intensity, duration of exercise required, aspects of cognition, and learner characteristics affect the relationship between physical activity and cognitive performance. For example, Sibley and Etnier's (2003) meta-analysis revealed a positive impact on children's cognition, which did not differ as a function of the type of physical activity (i.e., resistance training, perceptual-motor training, physical education classes, and aerobic exercises) on children's cognition. The effect of physical activity on cognitive performance was the greatest for children in the young elementary and middle school age group. The effect of physical activity on children's cognition differed significantly on the type of cognitive assessment used. The largest effect was found for assessments on perceptual skills, followed by IQ, academic achievement, and math and verbal tests. Furthermore, a meta-analysis by Chang et al. (2012) showed that acute bouts of exercise can have beneficial effects on cognitive tasks executed during, immediately after, or after a delay following the exercise. Short bouts of exercise affect cognitive processes by increasing response speed and accuracy (Tomporowski 2003), 
improving working memory capacity (Pontifex et al. 2009), as well as improved performance on free-recall tasks (Coles and Tomporowski 2008). For example, Drollette et al. (2014) showed that, after $20 \mathrm{~min}$ of treadmill walking, preadolescent children had better performance on cognitive tasks gauging attention and inhibitory control compared with children who remained seated.

\section{Effects of Part-Body Movements}

More subtle movements, such as gestures, are typically integrated into the learning task and are only effective when they are meaningful for or congruent with the learning task (Kelly et al. 2009; Macedonia and Klimesch 2014; Trofatter et al. 2015). There is increasing evidence that gesturing has positive effects on learning of different types of cognitive tasks, such as math (e.g., Cook et al. 2008; Goldin-Meadow et al. 2001; Novack et al. 2014), and language (e.g., Allen 1995; Kelly et al. 2009; Macedonia and Klimesch 2014; Tellier 2008; Thomas and Lleras 2009; Trofatter et al. 2015).

The theoretical framework of grounded or embodied cognition has been used to explain the positive effects of this type of movement on learning. Embodied cognition is based on the notion that cognitive processes develop from goal-directed interactions between organisms and their environment (Barsalou 1999, 2008; Glenberg 1997). It assumes that cognitive processes are grounded in perception and action (Barsalou 1999). Ample evidence for the embodied cognition framework comes from psychological research in a variety of domains, such as research on action semantics (e.g., Lindemann et al. 2006), language comprehension (e.g., Zwaan and Taylor 2006), and neuroscience (e.g., Glenberg et al. 2008). This research shows that visual and motor processes in the brain are active during the performance of cognitive tasks such as reading, comprehension, mental arithmetic, and problem solving, while semantic codes are activated during the performance of motor tasks, suggesting that cognitive and sensorimotor processes are closely intertwined. An explanation for the positive effects on learning is that embodying knowledge through making gestures results in a distinct, visuospatial representational format that can enrich the way information is coded, i.e., the construction of higher quality cognitive schemas (Goldin-Meadow et al. 2001; Paas and Sweller 2012). Higher-quality cognitive schemas are associated with better and less cognitively demanding learning (Goldin-Meadow et al. 2001; Ping and Goldin-Meadow 2010), which materializes in faster and more accurate performance on a learning test. An alternative explanation holds that gesturing shifts some of the load from verbal working memory to other cognitive systems. This explanation is consistent with results from cognitive neuroscientific research showing that gesture is represented in cortical areas that differ from those that handle verbal materials (e.g., Decety et al. 1997).

Speech gestures, consisting of pantomimic and non-pantomimic gestures, can assist memory. Pantomimic gestures convey meaning even when verbal speech is absent (Cohen and Otterbein 1992). The present study focused on learning of a foreign language vocabulary by acting out the meaning of words through pantomimic or enactment gestures. Empirical work has demonstrated that meaningful engagement of the motor system during language processing enhanced memory encoding and retrieval. Performance on free-recall as well as cued recall tasks is better when the verbal instructions can be enacted while learning ("enactment effect": Cohen and Otterbein 1992; Engelkamp and Cohen 1991). Gestures have a representational function, connecting different modalities such as the verbal, visual and motor modality. 
Enactment effects induced by gestures promote deeper semantic or conceptual processing, facilitating memory performance of younger and older adults on recognition and cued recall tasks (Feyereisen 2009).

\section{Empirical Evidence}

Several studies have provided evidence for the positive effects of gestures on language learning. Macedonia and Klimesch (2014) showed that encoding of novel words from an artificial language was deeper when information was presented through enactment (involving gestures) rather than audiovisually. Tellier (2008) assessed learning vocabulary words from a foreign language. Preschool children had to either to listen and repeat each word, watch a gesture related to the word, and reproduce the gesture (gesture group), or listen and repeat a word, and watch a picture related to the word (picture group). She found that children in the gesture group performed better than children in the picture group in recall tests. Gesturing can be a powerful aid for long-term recall of complex learning such as learning first and foreign languages in preschool children (Rowe et al. 2013).

Previous research has also provided evidence for the positive effects of physical activity on language learning. Pesce et al. (2009) investigated the effects of physical activity on children's memorization of vocabulary words from a foreign language. They taught 11-12-yearold children words from a foreign language and examined their performance on immediate and delayed recall when they were engaged in circuit training, team games, or did not exercise at all. They concluded that acute bouts of physical activity might facilitate memory storage efficiency by minimizing rehearsal and shortening consolidation time. Focusing on the synergistic effects of physical activity and academic performance (Lees and Hopkins 2013), physical activity programs incorporating short bouts of acute exercise could be effectively applied during daily school schedules to promote physical activity and enhance cognitive performance in children (Drollette et al. 2014). The role of school-based physical activity programs in increasing physical activity during the school day either through recess or breaks or by integrating physical activity with academic content has been investigated in several studies (Bartholomew and Jowers 2011; Castelli et al. 2011; Davis et al. 2011; Donnelly and Lambourne 2011; Hillman et al. 2009; Kibbe et al. 2011; Lambourne et al. 2013; Mahar et al. 2006; Telford et al. 2012; Vazou and Smiley-Oyen 2014). In general, these studies report positive associations between physical activity and learning outcomes in elementary and high school children (Erwin et al. 2012). Classroom-based physical activity is considered an enjoyable way to promote physical activity and foster executive function in children (Vazou and Smiley-Oyen 2014).

However, there is a dearth of research in younger children in early childhood settings. Interventions in early years have tremendous effects on children's cognitive and social development (Ramey and Ramey 1998); therefore, it is considered important to examine the effects that can be found in this specific age group. One of the few intervention programs targeting preschool children found that when they were engaged in moderate to vigorous physical activity play, they showed better self-regulation skills, which resulted in higher math and literary achievement scores (Becker et al. 2014). Moreover, Trost et al. (2008) developed a "move and learn" intervention program integrating gross motor movements in all aspects of a preschool curriculum. They found that at the end of the intervention, children were more physically active and also showed more enthusiasm, and attention to the leaning tasks. 
However, learning outcomes were not measured in this study. In a review, Best (2010) concludes that aerobic exercise can have direct and beneficial effects on executive function, which is crucial for enhancing cognitive development and learning in early childhood.

\section{The Present Study}

Taken together, the results of the unrelated lines of research into the cognitive and physiological effects of part- and whole-body movements on learning suggest that an intervention combining both effects by integrating task-relevant physical exercises into the learning task could be more effective than interventions targeting only non-integrated physical exercises or task-relevant gestures. In this study, four conditions were compared to investigate this suggestion in preschool children.

The main hypothesis was that an integrated physical exercise condition in which children learn foreign language vocabulary by performing physical exercises to enact the meaning of those words would lead to the highest immediate and delayed retention performance. The integrated physical exercise condition was compared to a non-integrated physical exercise condition, a gesturing condition, and a conventional condition. In the non-integrated physical exercise condition, children performed physical exercises at the same intensity during learning, but unrelated to the learning task. In the gesturing condition, children enacted the actions indicated by the words to be learned by gesturing while remaining seated, and in the conventional condition children verbally repeated the words while remaining seated. Based on the results of previous research, it was expected that the non-integrated exercise condition and the gesturing condition would show higher immediate and delayed retention performance than the conventional condition. Finally, children in the two exercise conditions were expected to be equally active, but more active than children in the non-exercise conditions (i.e., gesturing and conventional condition).

\section{Method}

\section{Participants}

Participants were 125 preschool children (64 boys and 61 girls) with a mean age 4.94 years $(\mathrm{SD}=0.56)$. Fifteen childcare centers were recruited for this study. However, in the analysis 111 participants were included due to missing data. Participants were recruited from four childcare centers in total in the integrated, four centers in the non-integrated, four centers in the control condition and three childcare centers in the embodied condition. The study was approved by the Human Research Ethics Committee of the University of Wollongong. All parents completed a written consent form about their children's participation in the research. Only children who attended childcare for 2 days or more per week were eligible to participate in the study. Children who had prior knowledge or relatives speaking the Italian language at home were excluded from the study. Also, children with developmental disorders and/or learning difficulties did not participate in the study. The childcare centers were randomly assigned, in such a way that there were children from 3 to 4 centers in total per condition. The resulting number of participants in each condition was as follows: 31 in the integrated condition, 23 in the non-integrated condition, 31 in the gesturing condition, and 26 in the conventional condition. Children received stickers when they completed the activity and after testing as a reward for their effort. 


\section{Materials}

\section{Measurement of Memory Performance: Free-Recall and Cued Recall Tests}

Children were taught 14 words from a foreign language (i.e., Italian). The selected words were 'fast', 'slow', 'dance', 'soccer', 'broom', 'low', 'high', 'swim', 'fly', 'jump', 'march', 'catch', 'throw', and 'roll'. The selection of the words was based on every day actions familiar to the children. Also, it was reassured that the words in Italian were no more than three syllabi. The suitability of the chosen words in terms of pronunciation and meaning of the actions for preschool children was evaluated by a teacher with an Italian background. Each day, children were taught seven different words. The order of the to-be-learned words was counterbalanced across the different days and weeks. Static pictures with children doing the relevant activities were displayed to children. After the presentation of each word, the researcher pronounced the words in Italian and children repeated the words afterward. In the free-recall tests, children were asked how many and which words they could recall regardless of their presentation order. In the cued recall tests, children were shown the pictures and were asked to say the Italian word. The maximum score on the free-recall and cued recall test was 14 and the minimum score was 0 . For each correctly recalled word, children received 1 point.

\section{Measurement of Physical Activity}

Children were fitted with an accelerometer (Actigraph models GT1M, GT3X and GT3X+/BT, Pensacola, FL), which was positioned over the anterior aspect of the right hip. The accelerometer was attached on an elastic belt, which was worn around the waist. Children and parents were instructed via written consent forms that the accelerometer should be worn every day during the intervention lessons. Accelerometers are instruments measuring variations in time differences in force or acceleration and thus assessing the magnitude and volume of movement as a function of time. The accelerometer collects data known as activity "counts" measured in time sampling intervals or epochs (Cliff et al. 2009). Measurements with the Actigraph accelerometer have been found to be valid, and reliable in children aged 3-5 years (Cliff et al. 2009). Because of the sporadic and intermittent type of physical activity in children, we used epochs of $15 \mathrm{~s}$ to estimate time in higher intensity activity (moderate and vigorous-intensity physical activity; see, e.g., Rowlands 2007; Cliff et al. 2009). Lesson times were recorded and filters used to analyze only the data from the start to the end of the lesson each day. Data were reported as the average activity counts per minute, representing total physical activity or movement as a function of time during the lesson. Data were also reported as minutes spent in moderate and vigorous-intensity physical activity, as higher intensity physical activity might potentially be important for cognitive functioning in children (Davis et al. 2007). Age-appropriate cut-points (Pate et al. 2006) that have been shown to be the most accurate in young children (Janssen et al. 2013) were used to define activity intensity. Out of 790 cases of accelerometry data, 66 cases were removed, because some children did not wear the monitor during the whole intervention session.

\section{Design and Procedure}

A mixed 4 (condition: integrated, non-integrated, gesturing, conventional) $\times 3$ (time of testing; during, directly after, follow-up) experimental design with repeated measures on the latter factor was used. The dependent variables were children's performance on the free-recall and cued recall tests. 
The study consisted of three phases: instruction, learning, and testing.

Instruction phase. Children were presented once with each English word to ensure that they understood the meaning of all words. Instructions given to children lasted for $20 \mathrm{~min}$. Children were told that they would play a memory game, and that they had to listen carefully to the teachers' instructions. After these instructions, they were asked questions about what they had learned. It was explained to them that they had to repeat the words after the instructor and perform an activity at the end of each word.

Learning phase. Children were assigned to a condition at center level, as it was not feasible to randomize children across conditions within each center. There were four different conditions in which children were taught the Italian words by using a different approach. Each one of the seven words that were taught per day was presented once at a time for 1 min until finishing all the words. All the words were presented both auditory and visually. Children had to repeat each word after the word was presented by the instructor. The total duration of the learning phase was 4 weeks, consisting of one 15-min session per day for 2 days per week.

In the integrated physical exercise condition, children enacted the actions indicated by the words to be learned by physically exercising. For example, for the word "fly," children ran and moved their hands as if they were flying. The integrated physical exercise condition was a combination of the non-integrated physical exercise and gesturing condition. In the non-integrated physical exercise condition, children performed physical exercises at the same intensity during learning, but these were unrelated to the learning task. In this condition, children were running or walking for all the words regardless the meaning of the word. In the gesturing condition, children enacted the actions indicated by the words to be learned by pantomimic gestures while remaining seated. For example, for the word "fly," children moved their hands as if they were flying while they remained seated. In the conventional condition, children verbally repeated the words while remaining seated.

Testing phase. Children were tested individually on their ability to recall the Italian words. During testing, children were asked to verbally recall as many words as they could remember from the learning phases (free-recall test) and subsequently based on the presentations with the words (cued recall test). Words recalled were also considered correct when minor spelling errors or singular-plural substitutions had occurred. The total duration of the assessment was 15-20 min per child. The total number of words remembered in the free-recall and the number of correct words in the cued recall test were calculated separately for the week 2 (during), week 4 (directly after), and week 10 (follow-up).

In the assessment during the learning phase at the end of week 2, the possible short-term or acute effects of embodiment and physical activity on learning were examined. The assessment directly after the learning phase in week 4 occurred at the end of the intervention and evaluated the medium-term effects of embodiment and physical activity on children's ability to learn a foreign language. The final follow-up assessment was administered 6 weeks after the learning phase in week 10 to determine how well the words were maintained in the children's memory. Moreover, emphasis was put on observing children's learning progress. The assessments in the three different time periods were administered in identical form. 
A pilot study was first conducted by the researcher to test the efficacy and feasibility of the forthcoming procedure. The researcher performed the teaching and testing together with three research assistants, who had received a 4-h training session on how to teach and test children before the experiment.

\section{Results}

Mixed 4 (condition: integrated, non-integrated, gesturing, conventional) $\times 3$ (time of testing; during, directly after, follow-up) analyses of variance (ANOVAs) with condition as betweensubject variable and time of testing as within-subject variable were performed. The dependent variables were performance on free-recall and cued recall tests. ${ }^{1}$ Effect size was measured via partial eta squared, in which small, medium, and large effects were operationalized as 0.01 , 0.06, and 0.14, respectively (Cohen 1988).

\section{Free-Recall}

A mixed ANOVA was performed to examine the effects of condition and time of testing on the free-recall tests. Mauchly's test indicated that the assumption of sphericity was met, $\chi^{2}(2)=3.46$, $p=0.177$. The ANOVA showed that there was a main effect of time of testing, $F(2,214)=50.21$, $p \leq 0.001, \eta^{2}=0.33$, indicating that the scores on the free-recall test differed significantly across the weeks of measurement. Polynomial contrasts tests revealed that there was a quadratic relationship for the time of testing, $F(1,106)=74.12, p \leq 0.001, \eta^{2}=0.41$. From week 2 to week 4 , the number of recalled words increased, whereas from week 4 to week 10, it decreased. Children could recall more words in week $4(M=1.83, \mathrm{SD}=1.56)$ than in week $10(M=1.32, \mathrm{SD}=1.56)$, and more words than in week $2(M=0.48, \mathrm{SD}=0.73)$. Finally, children in week $2(M=0.48, \mathrm{SD}=0.73)$ could remember fewer words than in week $10(M=1.32, \mathrm{SD}=1.56)$. There was also a significant main effect of condition on free-recall test performance, $F(3,107)=5.14, p=0.002, \eta^{2}=0.13$ (see Table 1). Post hoc tests revealed that children in the integrated condition $(M=1.73, \mathrm{SD}=1.34)$ remembered more words than children in the non-integrated condition $(M=0.97, \mathrm{SD}=1.01), p=$ 0.006 , the gesturing condition $(M=1.24, \mathrm{SD}=1.35), p=0.049$, and the conventional condition $(M=0.77, \mathrm{SD}=0.90), p \leq 0.001$. There were no differences on free-recall test performance among children in the non-integrated condition $(M=0.97, \mathrm{SD}=1.01)$ and the gesturing condition $(M=$ $1.24, \mathrm{SD}=1.35), p=0.327$, as well as the non-integrated condition $(M=0.97, \mathrm{SD}=1.01)$ and the conventional condition $(M=0.77, \mathrm{SD}=0.90), p=0.473$, and between children in the gesturing condition $(M=1.24 \mathrm{SD}=1.35)$ and the conventional condition $(M=0.77 \mathrm{SD}=0.90), p=0.076$. Figure 1 displays the average total number of correctly recalled words. Finally, the interaction between time of testing and condition was not significant, $F(6,214)=1.98, p=0.070$.

\section{Cued Recall}

A mixed ANOVA was performed to examine the effects of condition and time of testing on the cued recall tests. Mauchly's test indicated that the assumption of sphericity was violated,

\footnotetext{
${ }^{1}$ Perceived task enjoyment and task complexity were also measured. There were no effects on these measures, and for reasons of length, we deleted this information from the manuscript. Statistics can be obtained from the first author.
} 
Table 1 Means and standard deviations for performance on the different types of tests for the different conditions as a function of times of testing

\begin{tabular}{|c|c|c|c|c|}
\hline \multirow[t]{2}{*}{ Type of test } & \multicolumn{4}{|c|}{ Time of testing } \\
\hline & $\begin{array}{l}\text { Week } 2 \\
M(\mathrm{SD})\end{array}$ & $\begin{array}{l}\text { Week } 4 \\
M(\mathrm{SD})\end{array}$ & $\begin{array}{l}\text { Week } 10 \\
M \text { (SD) }\end{array}$ & $\begin{array}{l}\text { Total } \\
M \text { (SD) }\end{array}$ \\
\hline \multicolumn{5}{|l|}{ Free recall $(0-14)$} \\
\hline Integrated condition & $0.98(0.81)$ & $2.63(1.81)$ & $1.58(1.41)$ & $1.73(1.34)$ \\
\hline Non-integrated condition & $0.13(0.34)$ & $1.65(1.15)$ & $1.13(1.55)$ & $0.97(1.01)$ \\
\hline Gesturing condition & $0.39(0.72)$ & $1.71(1.40)$ & $1.61(1.93)$ & $1.24(1.35)$ \\
\hline Conventional condition & $0.31(0.62)$ & $1.19(0.98)$ & $0.81(1.10)$ & $0.77(0.90)$ \\
\hline \multicolumn{5}{|l|}{ Cued recall $(0-14)$} \\
\hline Integrated condition & $1.81(1.38)$ & $5.61(2.79)$ & $4.58(2.58)$ & $4.00(2.25)$ \\
\hline Non-integrated condition & $1.07(0.83)$ & $4.30(1.67)$ & $4.24(2.16)$ & $3.20(1.55)$ \\
\hline Gesturing condition & $1.15(1.10)$ & $4.37(2.22)$ & $4.00(2.81)$ & $3.17(2.04)$ \\
\hline Conventional condition & $0.71(1.15)$ & 3.15 (1.77) & $2.40(1.56)$ & $2.09(1.49)$ \\
\hline
\end{tabular}

$\chi^{2}(2)=22.83, p \leq 0.001$. Therefore, the degrees of freedom were corrected using GreenhouseGeisser estimates of sphericity $(\varepsilon=0.84)$. The results showed that performance on the cued recall tests was differentially affected by the time of testing, $F(1.68,179.26)=153.16, p \leq$ $0.001, \eta^{2}=0.59$. Polynomial contrasts revealed a quadratic relationship for time of testing, $F(1$, $107)=175.39, p \leq 0.001, \eta^{2}=0.62$. From week 2 to week 4 , the number of recalled words increased, whereas from week 4 to week 10, it decreased. Children could recall more words in week $4(M=4.42, \mathrm{SD}=2.35)$ than in week $10(M=3.84, \mathrm{SD}=2.48)$, and in week $2(M=1.21$, $\mathrm{SD}=1.20)$. There was also a significant main effect of condition on cued recall test performance, $F(3,107)=6.74, p \leq 0.001, \eta^{2}=0.16$ (Table 1$)$. Post hoc tests revealed that children in

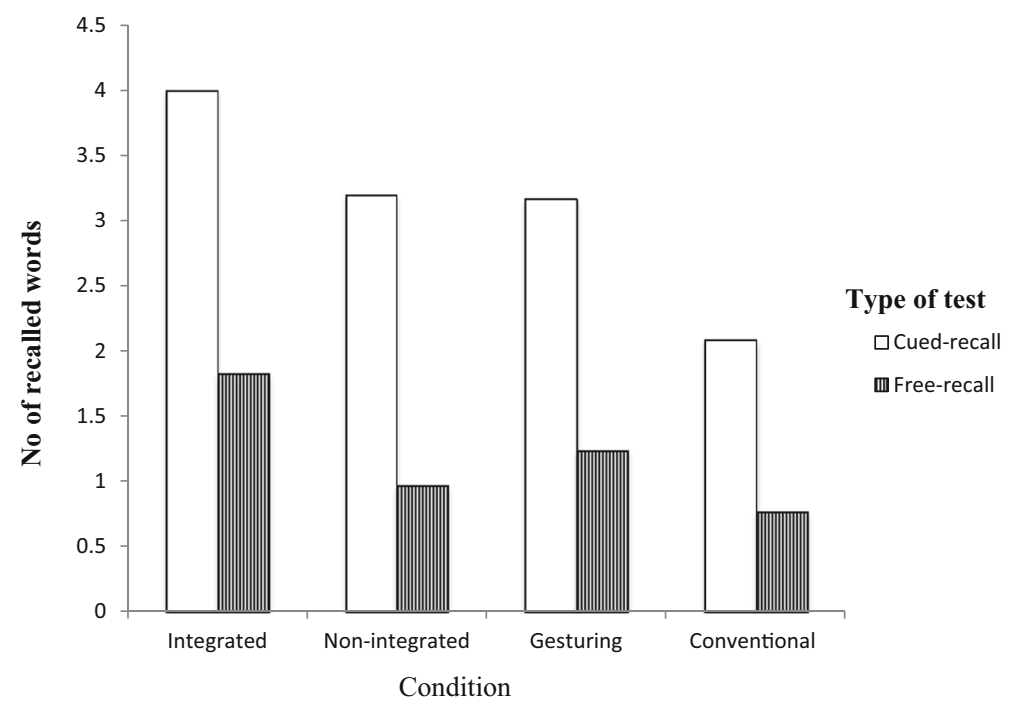

Fig. 1 Average total number of correctly recalled words on the free-recall and cued recall tests in the different conditions 
the integrated condition $(M=4.00, \mathrm{SD}=2.25)$ remembered more words than children in the gesturing condition $(M=3.17, \mathrm{SD}=2.04), p=0.044$, and in the conventional condition $(M=$ $2.09 \mathrm{SD}=1.49), p \leq 0.001$. There were no significant differences between children in the nonintegrated condition $(M=3.20, \mathrm{SD}=1.55)$ and the integrated condition $(M=4.00, \mathrm{SD}=2.25)$, $p=0.073$, as well as the non-integrated $(M=3.20, \mathrm{SD}=1.55)$ and the gesturing condition $(M=$ $3.17, \mathrm{SD}=2.04), p=0.944$. Children in the non-integrated condition remembered more words $(M=3.20, \mathrm{SD}=1.55)$ than children in the conventional condition $(M=2.09, \mathrm{SD}=1.49), p=$ 0.17 , and children in the gesturing condition $(M=3.17, \mathrm{SD}=2.04)$ remembered more words than children in the conventional condition $(M=2.09, \mathrm{SD}=1.49), p=0.012$ (see Fig. 1). Finally, the interaction between time of measurement and condition was not significant, $F(5.03$, 179.26) $=2.45, p=0.085$.

\section{Physical Activity}

Two separate ANOVAs were performed to assess the levels of physical activity across the different conditions and verify that the level of physical activity did not differ between the integrated and non-integrated exercise conditions. In addition, the analysis was used to verify whether the children in the exercise conditions were more active than the children in the gesturing and conventional condition. The units of measurement of level of physical activity were counts per minute as well as minutes of moderate- to vigorous-intensity physical activity (Pate et al. 2006). Results showed that there was a significant effect of condition on counts per minute, $F(3,720)=39.73 p \leq 0.001, \eta^{2}=0.14$. Post hoc tests with Games-Howell correction revealed that there were no differences found between the integrated condition $(M=938.07$, $\mathrm{SD}=552.76)$ and the non-integrated condition $(M=807.56, \mathrm{SD}=552.76), p=0.238$, and between the gesturing condition $(M=517.57, \mathrm{SD}=348.89)$, and the conventional condition $(M=$ $534.66, \mathrm{SD}=311.32), p=0.957$. Both in the integrated condition $(M=938.07, \mathrm{SD}=552.76)$ and the non-integrated condition $(M=807.56, \mathrm{SD}=552.76)$ more counts per minute were recorded than in the gesturing condition $(M=517.57, \mathrm{SD}=348.89), p \leq 0.001$, and the conventional condition $(M=534.66, \mathrm{SD}=311.32), p \leq 0.001$.

There was a significant effect of condition on the total time spent in moderate-to-vigorousintensity physical activity (MVPA), $F(3,720)=35.20, p \leq 0.001, \eta^{2}=0.13$. Post hoc tests with Games-Howell correction revealed that there were no differences in time spent in MVPA between the integrated condition $(M=3.85 \mathrm{SD}=3.20)$ and the non-integrated condition $(M=$ $3.47, \mathrm{SD}=3.40), p=0.759$, and between the gesturing condition $(M=1.92, \mathrm{SD}=1.68)$, and the conventional condition $(M=1.75, \mathrm{SD}=1.17), p=0.656$. Both in the integrated condition $(M=$ 3.85 $\mathrm{SD}=3.20)$ and the non-integrated condition $(M=3.47, \mathrm{SD}=3.40)$ children spent more time on MVPA than children in the gesturing $(M=1.92, \mathrm{SD}=1.68), p \leq 0.001$, and conventional condition $(M=1.75, \mathrm{SD}=1.17), p \leq 0.001$.

\section{Discussion}

The main goal of this study was to investigate the effects of enacting words through full-body movements in the form of physical exercise and part-body movements in the form of gesturing on learning a foreign language vocabulary. The results confirmed the hypotheses, indicating that the integrated condition, in which children used physical exercises to enact words to be learned, outperformed all other conditions for free-recall performance. For cued recall 
performance, similar results were obtained, but the results of the children in the integrated physical exercise condition did not differ from those of the children in the non-integrated physical exercise condition.

Overall, the scores on the tests were very low, even on the cued recall test. This can be attributed to the fact that learning a foreign language vocabulary can be considered a very difficult task for 4- to 5-year-old children. Most importantly, children were exposed to the Italian words only during the learning phase and no other stimuli were provided to them during the day. Possibly, longer learning sessions and greater exposure during the day (e.g., more repetitions) would be needed to achieve higher performance scores. The results on the free-recall test, which can be considered more difficult than the cued recall test, revealed that the integrated condition outperformed all other conditions during, directly after, and 6 weeks after the learning phase. Although children in the non-integrated and the gesturing condition showed higher performance than children in the control group, these differences were not significant. On the cued recall task, all conditions outperformed the conventional condition. The integrated condition outperformed the gesturing condition, but not the non-integrated exercise condition. In addition, cued recall performance in the non-integrated and gesturing condition did not differ. In both free-recall and cued recall tests, performance was the highest in the integrated condition, followed by non-integrated, gesturing and conventional condition. The pattern was the same for the delayed test, followed by the follow-up and lastly the immediate test.

In general, the results of the integrated and gesturing conditions indicate that children's learning of a foreign language vocabulary is positively affected by the cognitive effects of enacting the words through physical exercises or gestures. The positive effects on learning of the non-integrated physical exercise condition are reflective of the physiological effects of physical activities. Interestingly, the results indicate that embodying knowledge through physical exercises that are integrated in the learning task is a particularly effective learning strategy in young children. It is also clear that the effectiveness of this strategy is caused its integrated character, because physical exercise of the same intensity in the non-integrated condition resulted in lower free recall performance. This study corroborates findings of previous studies that accentuate the benefits of physical activity on learning and programs that successfully integrated physical activity into school classrooms in older children and elicited positive effects on academic achievement (Kibbe et al. 2011). At the same time, the principles of the embodied cognition framework were confirmed by the positive effects of movements in the form of physical exercise and gestures on learning performance. This study provided a unique contribution to the existing research literature by testing the effects of an integrated intervention program for preschool children, which integrated physical exercises into the learning task.

An alternative explanation for the effectiveness of the integrated physical activities and gestures on learning is that participants in these conditions not only made movements, but also observed other classmates making movements, because of the classroom-based experimental setup. Episodic memory is based on the storage and retrieval of temporally dated, spatially located, and personally experienced events or episodes. Episodic information about a word is the information about the event of which the word was the crucial element (Tulving and Thomson 1973). Observing others' movements could support episodic memories as encoding of the words relied on the context or the situation elements. Moreover, numerous studies have shown that observing gestures can have positive effects on learning (e.g., Church et al. 2004; Cook et al. 2013; Ping and Goldin-Meadow 2008). According to research on the mirror neuron system, when 
people look at others' people actions, they activate neurons that are related to the same action in the motor cortex (Rizzolatti and Craighero 2004). In the present study, children in the integrated condition may have activated the relevant neurons linked with the physical activity actions in their motor cortex, which enhanced by the gestures, transformed that information into knowledge (Rizzolatti and Craighero 2004). Future research could investigate whether the same effects on learning can be observed during individual learning sessions. This would provide the opportunity to differentiate effects of performing and observing movements on learning.

It is clear that more evidence needs to be obtained in replication studies to be conclusive about the positive effects of integrated physical exercise on children's learning. In addition, similar future studies in the other domains, such as math and science, and with other target groups, such as adolescents, need to be conducted to determine whether the current results can be generalized across domains and target groups.

The current study has important educational implications. The results suggest that adding gestures or physical exercise to the learning of cognitive tasks leads to better learning than conventional strategies in which students learn by reading or listening to learning materials. The integration of physical activity into a language learning task by asking children to enact words through physical exercises seems especially effective for learning. An additional benefit of regular physical exercise, which has been found in previous research, is its positive effect on children's physical and mental health. Therefore, implementing integrated physical exercises in early education programs can be expected to have pervasive long-term effects on achievement and academic success especially for children from low-SES backgrounds (Barnett 1998).

\section{References}

Allen, L. Q. (1995). The effects of emblematic gestures on the development and access of mental representations of French expressions. The Modern Language Journal, 79(4), 521-529.

Barenberg, J., Berse, T., \& Dutke, S. (2011). Executive functions in learning processes: do they benefit from physical activity? Educational Research Review, 6(3), 208-222.

Barnett, W. S. (1998). Long-term cognitive and academic effects of early childhood education on children in poverty. Preventive Medicine, 27(2), 204-207.

Barsalou, L. W. (1999). Perceptions of perceptual symbols. Behavioral and Brain Sciences, 22(04), 637-660.

Barsalou, L. W. (2008). Grounded cognition. Annual Review of Psychology, 59, 617-645.

Bartholomew, J. B., \& Jowers, E. M. (2011). Physically active academic lesson in elementary children. Preventive Medicine, 52, S51-S54.

Becker, D. R., McClelland, M. M., Loprinzi, P., \& Trost, S. G. (2014). Physical activity, self-regulation, and early academic achievement in preschool children. Early Education \& Development, 25(1), 56-70.

Best, J. R. (2010). Effects of physical activity on children's executive function: contributions of experimental research on aerobic exercise. Developmental Review, 30(4), 331-351.

Castelli, D. M., Hillman, C. H., Hirsch, J., Hirsch, A., \& Drollette, H. E. (2011). FIT Kids: time in target heart zone and cognitive performance. Preventive Medicine, 52(Suppl: 1), S55-S59.

Chang, Y. K., Labban, J. D., Gapin, J. I., \& Etnier, J. L. (2012). The effects of acute exercise on cognitive performance: a meta-analysis. Brain Research, 1453, 87-101.

Church, R. B., Ayman-Nolley, S., \& Mahootian, S. (2004). The role of gesture in bilingual education: does gesture enhance learning? International Journal of Bilingual Education and Bilingualism, 7(4), 303-319.

Cliff, D. P., Reilly, J. J., \& Okely, A. D. (2009). Methodological considerations in using accelerometers to assess habitual physical activity in children aged 0-5 years. Journal of Science and Medicine in Sport, 12(5), 557-567.

Cohen, J. (1988). Statistical power analysis for the behavioral sciences (2nd ed.). Hillsdale: Erlbaum.

Cohen, R. L., \& Otterbein, N. (1992). The mnemonic effect of speech gestures: pantomimic and non-pantomimic gestures compared. European Journal of Cognitive Psychology, 4(2), 113-139.

Coles, K., \& Tomporowski, P. D. (2008). Effects of acute exercise on executive processing, short-term and longterm memory. Journal of Sports Sciences, 26(3), 333-344. 
Cook, S. W., Mitchell, Z., \& Goldin-Meadow, S. (2008). Gesturing makes learning last. Cognition, 106, 1047-1058.

Cook, S. W., Duffy, R. G., \& Fenn, K. M. (2013). Consolidation and transfer of learning after observing hand gesture. Child Development, 84(6), 1863-1871.

Davis, C. L., Tomporowski, P. D., Boyle, C. A., Waller, J. L., Miller, P. H., Naglieri, J. A., \& Gregoski, M. (2007). Effects of aerobic exercise on overweight children's cognitive functioning: a randomized controlled trial. Research Quarterly for Exercise and Sport, 78(5), 510-519.

Davis, C. L., Tomporowski, P. D., McDowell, J. E., Austin, B. P., Miller, P. H., Yanasak, N. E., Allison, J. D., \& Naglieri, J. A. (2011). Exercise improves executive function and achievement and alters brain activation in overweight children: a randomized, controlled trial. Health Psychology, 30(1), 91-98.

Decety, J., Grezes, J., Costes, N., Perani, D., Jeannerod, M., Procyk, E., Grassi, F., \& Fazio, F. (1997). Brain activity during observation of actions. Influence of action content and subject's strategy. Brain, 120(10), 1763-1777.

Donnelly, J. E., \& Lambourne, K. (2011). Classroom-based physical activity, cognition, and academic achievement. Preventive Medicine, 52, S36-S42.

Drollette, E. S., Scudder, M. R., Raine, L. B., Moore, R. D., Saliba, B. J., Pontifex, M. B., \& Hillman, C. H. (2014). Acute exercise facilitates brain function and cognition in children who need it most: an ERP study of individual differences in inhibitory control capacity. Developmental Cognitive Neuroscience, 7, 53-64.

Engelkamp, J., \& Cohen, R. L. (1991). Current issues in memory of action events. Psychological Research, 53(3), 175-182.

Erickson, K. I., Hillman, C. H., \& Kramer, A. F. (2015). Physical activity, brain, and cognition. Current Opinion in Behavioral Sciences, 4, 27-32.

Erwin, H., Fedewa, A., Beighle, A., \& Ahn, S. (2012). A quantitative review of physical activity, health, and learning outcomes associated with classroom-based physical activity interventions. Journal of Applied School Psychology, 28(1), 14-36.

Fedewa, A. L., \& Ahn, S. (2011). The effects of physical activity and physical fitness on children's achievement and cognitive outcomes: a meta-analysis. Research Quarterly for Exercise and Sport, 82(3), 521-535.

Feyereisen, P. (2009). Enactment effects and integration processes in younger and older adults' memory for actions. Memory, 17(4), 374-385.

Glenberg, A. M. (1997). What memory is for: creating meaning in the service of action. Behavioral and Brain Sciences, 20(01), 41-50.

Glenberg, A. M., Sato, M., Cattaneo, L., Riggio, L., Palumbo, D., \& Buccino, G. (2008). Processing abstract language modulates motor system activity. The Quarterly Journal of Experimental Psychology, 61(6), 905-919.

Goldin-Meadow, S., Nusbaum, H., Kelly, S. D., \& Wagner, S. (2001). Explaining math: gesturing lightens the load. Psychological Science, 12(6), 516-522.

Goldin-Meadow, S., Cook, S. W., \& Mitchell, Z. A. (2009). Gesturing gives children new ideas about math. Psychological Science, 20(3), 267-272.

Hillman, C. H., Erickson, K. I., \& Kramer, A. F. (2008). Be smart, exercise your heart: exercise effects on brain and cognition. Nature Reviews Neuroscience, 9(1), 58-65.

Hillman, C. H., Pontifex, M. B., Raine, L. B., Castelli, D. M., Hall, E. E., \& Kramer, A. F. (2009). The effect of acute treadmill walking on cognitive control and academic achievement in preadolescent children. Neuroscience, 159, 1044-1054.

Janssen, X., Cliff, D. P., Reilly, J. J., Hinkley, T., Jones, R. A., Batterham, M., Ekelund, U., Brage, S., \& Okely, A. D. (2013). Predictive validity and classification accuracy of ActiGraph energy expenditure equations and cut-points in young children. PLoS ONE, 8(11), e79124.

Kelly, S. D., McDevitt, T., \& Esch, M. (2009). Brief training with co-speech gesture lends a hand to word learning in a foreign language. Language and Cognitive Processes, 24(2), 313-334.

Kibbe, D. L., Hackett, J., Hurley, M., McFarland, A., Schubert, K. G., Schultz, A., \& Harris, S. (2011). Ten years of TAKE 10!: integrating physical activity with academic concepts in elementary school classrooms. Preventive Medicine, 52, S43-S50.

Lambourne, K., Hansen, D. M., Szabo, A. N., Lee, J., Herrmann, S. D., \& Donnelly, J. E. (2013). Indirect and direct relations between aerobic fitness, physical activity, and academic achievement in elementary school students. Mental Health and Physical Activity, 6(3), 165-171.

Lees, C., \& Hopkins, J. (2013). Effect of aerobic exercise on cognition, academic achievement, and psychosocial function in children: a systematic review of randomized control trials. Preventive Chronic Disease, 10 , E174.

Lindemann, O., Stenneken, P., Van Schie, H. T., \& Bekkering, H. (2006). Semantic activation in action planning. Journal of Experimental Psychology: Human Perception and Performance, 32(3), 633-643.

Liu-Ambrose, T., Nagamatsu, L. S., Voss, M. W., Khan, K. M., \& Handy, T. C. (2012). Resistance training and functional plasticity of the aging brain: a 12-month randomized controlled trial. Neurobiology of Aging, 33, 1690-1698.

Macedonia, M., \& Klimesch, W. (2014). Long-term effects of gestures on memory for foreign language words trained in the classroom. Mind, Brain and Education, 8(2), 74-88. 
Mahar, M. T., Murphy, S. K., Rowe, D. A., Golden, J., Shields, A. T., \& Raedeke, T. D. (2006). Effects of a classroom-based program on physical activity and on-task behavior. Medicine \& Science in Sports \& Exercise, 38(12), 2086-2094.

Novack, M. A., Congdon, E. L., Hemani-Lopez, N., \& Goldin-Meadow, S. (2014). From action to abstraction: using the hands to learn math. Psychological Science, 25(4), 903-910.

Paas, F., \& Sweller, J. (2012). An evolutionary upgrade of cognitive load theory: using the human motor system and collaboration to support the learning of complex cognitive tasks. Educational Psychology Review, 24(1), 27-45.

Pate, R. R., Almeida, M. J., McIver, K. L., Pfeiffer, K. A., \& Dowda, M. (2006). Validation and calibration of an accelerometer in preschool children. Obesity, 14(11), 2000-2006.

Pesce, C., Crova, C., Cereatti, L., Casella, R., \& Bellucci, M. (2009). Physical activity and mental performance in preadolescents: effects of acute exercise on free-recall memory. Mental Health and Physical Activity, 2(1), 16-22.

Ping, R. M., \& Goldin-Meadow, S. (2008). Hands in the air: using ungrounded iconic gestures to teach children conservation of quantity. Developmental Psychology, 44(5), 1277-1287.

Ping, R., \& Goldin-Meadow, S. (2010). Gesturing saves cognitive resources when talking about non-present objects. Cognitive Science, 34(4), 602-619.

Pontifex, M. B., Hillman, C. H., Fernhall, B., Thompson, K. M., \& Valentini, T. A. (2009). The effect of acute aerobic and resistance exercise on working memory. Medicine \& Science in Sports \& Exercise, 41(4), 927-934.

Ramey, C. T., \& Ramey, S. L. (1998). Early intervention and early experience. American Psychologist, 53(2), 109.

Rizzolatti, G., \& Craighero, L. (2004). The mirror-neuron system. Annual Review Neuroscience, 27, $169-192$.

Rowe, M. L., Silverman, R. D., \& Mullan, B. E. (2013). The role of pictures and gestures as nonverbal aids in preschoolers' word learning in a novel language. Contemporary Educational Psychology, 38(2), 109-117.

Rowlands, A. V. (2007). Accelerometer assessment of physical activity in children: an update. Pediatric Exercise Science, 19(3), 252-266.

Sallis, J. F., McKenzie, T. L., Alcaraz, J. E., Kolody, B., Faucette, N., \& Hovell, M. (1997). The effects of a 2year physical education program (Spark) on physical activity and fitness in elementary school students. Sports, play and active recreation for kids. American Journal of Public Health, 87, 1328-1334.

Sibley, B. A., \& Etnier, J. L. (2003). The relationship between physical activity and cognition in children: a metaanalysis. Pediatric Exercise Science, 15, 243-256.

Telford, R. D., Cunningham, R. B., Fitzgerald, R., Olive, L. S., Prosser, L., Jiang, X., \& Telford, R. M. (2012). Physical education, obesity, and academic achievement: a 2-year longitudinal investigation of Australian elementary school children. American Journal of Public Health, 102(2), 368-374.

Tellier, M. (2008). The effect of gestures on second language memorization by young children. Gesture, 8(2), 219-235.

Thomas, L. E., \& Lleras, A. (2009). Swinging into thought: directed movement guides insight in problem solving. Psychonomic Bulletin \& Review, 16, 719-723.

Tomporowski, P. D. (2003). Effects of acute bouts of exercise on cognition. Acta Psychologica, 112, $297-324$.

Tomporowski, P. D., Davis, C. L., Miller, P. H., \& Naglieri, J. A. (2008). Exercise and children's intelligence, cognition, and academic achievement. Educational Psychology Review, 20, 111-131.

Trofatter, C., Kontra, C., Beilock, S., \& Goldin-Meadow, S. (2015). Gesturing has a larger impact on problemsolving than action, even when action is accompanied by words. Language, Cognition and Neuroscience, $30,251-260$.

Trost, S. G., Fees, B., \& Dzewaltowski, D. (2008). Feasibility and efficacy of a «Move and Learn» physical activity curriculum in preschool children. Journal of Physical Activity and Health, 5, 88-103.

Tulving, E., \& Thomson, D. M. (1973). Encoding specificity and retrieval processes in episodic memory. Psychological Review, 80(5), 352-373.

United Nations Educational, Scientific and Cultural Organisation. (2015). Physical education for healthier, happier, longer and more productive living [Press release]. Retrieved from http://www.unesco.org/new/en/ media-services/single-view/news/physical_education_for_healthier_happier_longer_and_more_productive living/\#.VOw2L0sz6Ew

United States. Department of Health, \& Human Services. (1996). Physical activity and health: a report of the Surgeon General. DIANE Publishing.

Vazou, S., \& Smiley-Oyen, A. (2014). Moving and academic Learning are not antagonists: acute effects on executive function and enjoyment. Journal of Sport and Exercise Psychology, 36, 474-485.

Zwaan, R. A., \& Taylor, L. J. (2006). Seeing, acting, understanding: motor resonance in language comprehension. Journal of Experimental Psychology: General, 135(1), 1-11. 